\title{
EFEITOS DO PERÍODO DE MATOCOMPETIÇÃO SOBRE A PRODUTIVIDADE DO AMENDOIM (Arachis hipogaea L.)
}

\author{
R.A. PITELLI*, E.C. FERRAZ ** $\mathrm{e}$ \\ G. DE MARINIS*** \\ * Professor Assistente, FCAV/UNESP-Jabotica- \\ bal - SP \\ ** Professor Assistente Doutor, ESALQ/USP-Pi- \\ racicaba - SP \\ *** Professor Titular, IB/UNESP-Rio Claro - SP
}

\section{RESUMO}

Com o objetivo de estudar os efeitos de diferentes períodos de competição das plantas daninhas sobre alguns parâmetros produtivos da cultura do amendoim cv. Tatu-53, foi instalada e conduzida a presente pesquisa, em Jaboticabal, em solo Latossol Vermelho Escuro - fase arenosa.

O delineamento experimental utilizado foi o de blocos casualizados, sendo os tratamentos divididos em dois grupos: no primeiro, a cultura foi mantida no mato desde a germinação até determinada fase de seu ciclo de desenvolvimento e, no segundo a cultura foi conservada livre da competição por períodos equivalentes ao primeiro grupo, após o qual o mato foi deixado crescer livremente. As extensões dos períodos estudados foram, $0,10,20,30,40,50,60,70,80,90$ e 100 dias.

Nas condições em que foi desenvolvido o experimento, o amendoim mostrou-se relativamente tolerante à competição de maneira que um período de 10 dias livre das plantas daninhas no início de seu ciclo de desenvolvimento proporcionou-lhe condicões plenas de produtividade, comparada à testemunha no limpo. Por outro lado, quand o foi pe rmitido que o mato desenvolvesse desde o início do ciclo de cultura, o período acima do qual a competição alterou a produtivi dade de cultura foi igual ou superior a 50 dias.

PALAVRAS CHAVE: Arachis hypogaeae,

matocompetição.

\section{SUMMARY}

EFFECTS OF WEED COMPETITION PERIOD ON PEANUT (Arachis hipogaea L.

With the objective of studying the effects of weed competition period over some productive parameters of peanut crop cv. Tatu-53, it was carried out the present research in Jaboticabal in a "Red Dark Latosol soil-sandy phase".

The experimental design used was the Randomized block being treatments devided in two groups: in the first, the crop was maintained in weed competition since the germination up to a specific point of its development cycle and in the second one it was maintained free of weed competition in equivalent periods to the first group, after the weeds were permitted to grow freely. The periods extensions studied were 0,10 , 20, 30, 40, 50, 60, 70, 80, 90 and 100 days.

The peanut crop have show relatively tole rant to the weed competition, and a period of ten days of weed free in the begining of it development cycle proportionated full productivity when compared with the treatment maintened free of competition. In relation to the initial period in competition the results, indicate the period after the flowering in general is critics, generally after the 50 days of the crop development cycle.

KEYWORDS: Arachis hypogaea, weed com-

petition.

\section{INTRODUÇÃO}

Segundo esquema citado por Blanco (4), o grau de competição na associa ção mato-cultura, depende da intervenção de fatores ligados tanto à comunidade infestante (composição específica, densidade e distribuição) como à própria cultura (género, espécie ou cultivar, espaçamento entre sulcos e densidade de semeadura). Além disso, depende também da época e duração do periodo em que permanecem juntas a cultura e a comunidade infestante e é modificado pelas condições edáficas, climáticas e tratos culturais.

Em amendoim, quase todos esses fatores foram passiveis de estudo. Verificou-se que cultivares de porte ereto- 
geralmente são menos susceptiveis à matocom petição que cultivares prostadas (09) e menor espaçamento entre sul cos de semeadura, proporciona maior competitividade à cultura, aumentando a eficiência das medidas de controle do mato $(09,12$ e 13). A densidade da comunidade infestante também é um dos principais fatores determinando o grau de competição na interação mato-amendoim $(08,14$ e 24). A importância da composição es pecífica do mato no grau de competição é relevante, pois as diferentes espécies daninhas apresentam grande variação na capacidade de recrutamento dos recursos do meio variando a forma e intensidade de competição sobre a cultura do amendoim, como pode ser observado nos trabalhos de Hauser et al. (13). Buchanam et al. (06) e York \& Coble (24).

Os efeitos da associação entre plantas daninhas e a cultura do amendoim podem ser incrementados ou minimizados por algumas práticas culturais conforme verificaram Hauser \& Parham (14), Hauser et al. (13), Feakin (09) e Bianco (03) e Buchanan et al. (06), e em determinadas condições climáticas específicas (09 e 10).

$\mathrm{O}$ período em que a cultura do amendoim deve ser mantida no limpo ou o periodo em que a cultura pode conviver com o mato, pelos motivos acima expostos, variam bastante dependendo principalmente do local $(13,06)$ e do ano agrícola $(15,13)$, levando as pesquisas a apresentarem resultados bastante diversos como pode ser observado nos trabalhos de Drennan e Jennings (08), Buchanan et al (06), Bhan et al (02), Hauser et al (13), Hill \& Santelman (15), York \& Coble (24) e Pacheco (20). Este fato, em parte, justifica a realização do presente trabalho, onde procurou-se estudar os efeitos de diferentes extensões e épocas do período de matocompetição sobre alguns parâmetros produtivos da cultura do amendoim.

\section{MATERIAIS E MÉTODOS}

O presente experimento foi instalado e conduzido em Jaboticabal (SP), em solo Latos- solo Vermelho Escuro fase arenosa, Série Santa Tereza (1) que apresentou $\mathrm{pH} 5,8$, contendo $0,69 \%$ de C, 0,094 e.mg de $\mathrm{PO}_{4}^{-2}, 0,14$ e.mg de $\mathrm{K}^{+}, 2,08$ e.mg de $\mathrm{Ca}++, 0,64$ e.mg de $\mathrm{Mg}^{++}, 0,096$ e.mg de $\mathrm{Al}^{+++}$e 2,64 e.mg de $\mathrm{H}^{+} / 100 \mathrm{~g}$ de TFSE.

Considerando a desuniformidade do mato na área experimental, o ensaio, no campo, foi montado segundo o delineamento experimental de blocos casualizados com três repetições. Os tratamentos foram constituídos em 2 grupos. No primeiro, a cultura permaneceu livre da matocompetição desde a germinação até diferentes êpocas de seu ciclo de desenvolvimento, após o qual o mato foi deixado crescer livremente. No segundo grupo, foi permitido que a cultura desenvolvesse em competição com as plantas daninhas por períodos equivalentes ao primeiro grupo. As extensões dos períodos estudados foram $00,10,20,30,40,50$, 60, 70, 80 e 100 dias. Cada parcela foi constituida de 5 linhas de semeadura de 5 metros de comprimento.

A semeadura foi realizada no dia 23 de outubro de 1976, utilizando-se a cultivar Tatu-53, depositando-se 30 sementes por metro linear de sulco, os quais eram espaçados de $0,60 \mathrm{~m}$ e a adubação de plantio foi $300 \mathrm{~kg} / \mathrm{ha}$ da fórmula 04-3411 .

Nos tratamentos em que a cultura permane ceu um período inicial no limpo, a cada 10 dias, para os tratamentos respectivos, colhia-se as plantas daninhas presentes em uma área de 0,32 $\mathrm{m}^{2}$ centrais de cada parcela, as quais eram identificadas e secas em estufa de circulação forçada de ar à $70-80^{\circ} \mathrm{C}$ até peso constante. No outro grupo de tratamentos, o mesmo procedimento foi obedecido por ocasião da colheita da cultura, ou seja, em 27/02/1977.

Foram colhidas e contadas as plantas da cultura na área útil das parcelas experimentais $(5,4$ $\mathrm{m}^{2}$ ). Após a secagem no campo avaliou-se o peso da produção de vagens e de sementes, o número médio de sementes por vagem, número de vagens por planta e peso médio de 100 sementes.

$\mathrm{Na}$ análise estatística dos dados, quando o teste $\mathrm{F}$ foi significativo, procedeu-se o desdobramento dos graus de liberdade dos tratamentos, comparando-se inicialmente os tratamentos que tiveram um período inicial no limpo com aqueles que tiveram um período inicial no mato. Para facilidade em expressar o contraste, utilizou-se, nas tabelas, a conotação "L contra M". Outro contraste foi realizado entre todos os tratamentos que tiveram um periodo inicial no limpo e um terceiro entre os que tiveram o período inicial no mato. As conotações utilizadas foram "Dentro L" e "Dentro M", respectivamente.

\section{RESULTADOS E DISCUSSÃO}

Os resultados mostram que as espécies ocorreram de modo mais ou menos indiferente em ambos os grupos de tratamentos, sendo que no grupo de tratamentos com um periodo inicial no limpo as populações foram menores, o 
que é lógico, uma vez que a avaliação foi feita após um periodo, se bem que variável, de controle destas plantas e no outro grupo as avaliações foram feitas antes que houvesse qualquer controle do mato. Segundo as obs ervações de Bhan et al. (02), a maior parte dos individuos componentes de uma comunidade infestante em amendoim, ge rminam nos primeiros 30 dias do ciclo de cultura. Então um controle inicial do mato diminue drasticamente os efetivos das populações compon en tes desta comunidade.

As principais espécies que ocorreram na área experimental, dispostas em ordem decrescentes de suas densidades populacionais, foram: Cenchrus echinatus L., Sida glaziovii (K.) Schuman, Richardia brasiliensis Gomez, Indigofera hirsuta L., Brachiaria plantaginea (Link.) Hitch, Digitaria sanguinalis (L.) Scop. e Tagetes minuta L.. A espécie da distribuição mais generalizada foi Sida glaziovii ocorrendo em
93,3\% das parcelas do primeiro grupo de tratamentos e em $75,8 \%$ no segundo grupo.

A matéria seca acumulada pelas plantas daninhas foi avaliada em conjunto e os resultados estão apresentados no Quadro 1. Considerando-se, para efeitos de comparação, apenas o tratamento com período total no mato, pode-se aquilatar que as infestações observadas são similares àquelas verificadas por Ishag (17). Acredita-se que os resultados apresentados pelos demais autores tenham sido tomados em termos de matéria fresca. Os valores observados foram bastante altos como $15,98 \mathrm{t} / \mathrm{ha}$ em 1975 e $22,39 \mathrm{t} / \mathrm{ha}$ em 1974 (24), 20,80 t/ha (14) e 11,00 t/ha em 1966 e 22,00 t/ha em 1967 (15).

No Quadro 2 estão apresentados os dados médios de peso da produção de vagens e de sementes por parcela de 5,4 $\mathrm{m}^{2}$ e dados de "stand" da cultura.

Com relação ao peso de vagens por parcela observou-se que os tratamentos

Quadro 1. Dados de peso médio da matéria seca acumulada pela comunidade infestante em $0,32 \mathrm{~m}^{2}$ da área útil das parcelas experimentais. Média de 3 repetiçóes.

\begin{tabular}{|c|c|c|c|c|}
\hline \multirow{3}{*}{$\begin{array}{l}\text { Tempo } \\
\text { (dias) }\end{array}$} & \multicolumn{4}{|c|}{ Peso da matéria seca $\left(g / 0,32 \mathrm{~m}^{2}\right)$} \\
\hline & \multicolumn{2}{|c|}{ Dados originais } & \multicolumn{2}{|c|}{ Transformados $1 \mathrm{n}(\mathrm{x}+1)$} \\
\hline & Mato & Limpo & Mato & Limpo \\
\hline 00 & - & 71,2 & - & $4,09 \mathrm{a}$ \\
\hline 10 & 2,5 & 19.5 & $1,22 \mathrm{~d}$ & $2,22 \mathrm{ab}$ \\
\hline 20 & 3,3 & 3,5 & $1,24 \mathrm{~cd}$ & $1,27 \mathrm{~b}$ \\
\hline 30 & 20,0 & 3,2 & $2,87 \mathrm{bod}$ & $1,24 \mathrm{~b}$ \\
\hline 40 & 17,8 & 3,1 & $2,84 \mathrm{bcd}$ & $1,26 \mathrm{~b}$ \\
\hline 50 & 26,5 & 2,1 & $3,02 \mathrm{bcd}$ & $1,19 \mathrm{~b}$ \\
\hline 60 & 32,4 & 0,6 & $3,39 \mathrm{abc}$ & $0,48 b$ \\
\hline 70 & 78,3 & 0,8 & $4.25 \mathrm{ab}$ & $0.52 b$ \\
\hline 80 & 72,3 & 3,1 & $4,12 \mathrm{ab}$ & $1,21 \mathrm{~b}$ \\
\hline 90 & 73,3 & 4,7 & $4,15 \mathrm{ab}$ & $1,44 \mathrm{~b}$ \\
\hline 100 & 231,1 & 1,0 & $5,39 \mathrm{a}$ & $0,56 \mathrm{~b}$ \\
\hline F blocos & & & & \\
\hline fratamentos & & & & \\
\hline Dentro $L$ & & & & \\
\hline Dentro $M$ & & & & \\
\hline 1 . nntra M & & & & \\
\hline C.V. $(\%)$ & & & & \\
\hline D.M.S. (5\%) & & & & \\
\hline
\end{tabular}

* significativo ao nível de $5 \%$ de probabilidade

* significativo ao nível de $1 \%$ de probabilidade

ns nầ significativo. 
diferiram significativamente entre si. O desdobramento dos graus de liberdade dos tratamentos mostrou que estas diferenças eram evidentes quando comparavam-se tratamentos que tiveram um período inicial no limpo com aqueles que tiveram um período inicial no mato. Além disso, dentro do grupo de tratamentos que tiveram um periodo inicial no mato, houve também, contrastes que diferiram significativamente. É claro que, pela própria natureza do trabalho, este último grupo de tratamentos sofreu mais intensamente os efeitos da competição. Em média, as parcelas que tiveram um período inicial no limpo apresentaram um peso de vagens $15,8 \%$ mais elevado em relação ao grupo de tratamentos com períodos iniciais no mato, indiferentemente dos comprimentos dos períodos.

A correlação entre o peso da produção de vagens e o tempo em que as parcelas permaneceram no mato foi significativa $\left(\mathrm{r}=0,83^{* *} ; \mathrm{V}=749,84-2,64 \mathrm{t}\right.$, onde $\mathbf{v}$ é a produção de vagens da parcela e t é o tempo, a partir da germinação, em que a cultura e -comunidade infestante permanecem em competição), indicando que o peso da produção de vagens decresce proporcionalmente ao tempo de competição, a partir da germinação ou plantio. Observou-se também, uma correlação significativa entre - peso da matéria seca acumulada pelas plantas daninhas por ocasião da eliminação da comunidade infestante e - peso da produção de vagens das parcelas corres pondentes $\left(\mathrm{r}=0,87^{* *} ; \mathrm{v}=\right.$ $=394,00-0,55 \mathrm{~m}$, onde $m$ é o peso da matéria seca das plantas daninhas).

A análise de regressão múltipla en tre estes três parâmetros foi significati va $\left(R^{2}=0,93^{* *}\right)$. A equação foi $\mathrm{v}=$ $=760,38-2,04 \mathrm{t}-0,63 \mathrm{~m}$, podendo-se verificar que o tempo de competição influiu em maior proporção na produção da cultura que o crescimento das plantas daninhas. Talvez isto se deva ao fato de que o próprio acúmulo de matéria seca das plantas daninhas de pendeu do tempo que a comunidade infestante teve para o desenvolvimento $\left(\mathrm{r}=0,81^{* *}\right.$, $\mathrm{m}=34,85+0,36 \mathrm{t})$.

Outro aspecto a ser observado neste grupo de tratamentos é o período mínimo de convivência múltipla culturamato, de maneira que a produção não seja alterada significativamente. Pode-se observar que um período de competição acima dos 50 dias torna-se crítico à produção da cultura. Quando se compara a média das produções obtidas nos tratamentos com períodos no mato inferiores a 50 dias com a média de períodos iguais ou superiores a este valor, observa-se uma diferença de produção em torno de 22,5\%, somente suplantado pela comparação entre a média do tratamento mantido no mato por 100 dias e a média dos demais tratamentos, sendo que naquele tratamento houve uma parcela de produção baixís sima, devido intensa infestação de Brachiaria plantaginea.

Este período situa-se no limite superior da faixa de valores encontrados na literatura o qual é devido ao trabalho de Bunting \& Lea (07). Valores superiores a este somente foram encontrados por Hauser et al. (13), estudando competição de plantas de amendoim com apenas uma espécie daninha, Cassia obtusifolia. Em estudo de competição com comunidades infestantes, os valores sempre foram inferiores.

Rodrigues Marquina et al. (22) justificam que ao redor de 60 dias após a semeadura, completa-se a maior parte do florescimento da cultura. A partir de então a competição torna-se mais crítica, concordando, em parte com os resultados do presente trabalho e com a observação de York e Coble (24) de que a grande interferência das plantas daninhas se manifesta na formação de vagem e enchimento das sementes. Bianco (03) praticamente confirma esta afirmação demonstrando que a competição influiu sensivelmente na formação das sementes de amendoim, aumentando a porcentagem de sementes mal granadas e diminuindo a participação de sementes perfeitamente granadas.

< É interessante considerar que, praticamente, este é o período em que os recursos do meio começam a ser limitados e a competição se instala. Este ponto depende de inúmeros fatores como a habilidade dos competidores em recrutar os recursos do meio, a própria abundância do meio em recursos, 
as condições de desenvolvimento e a própria abundância dos elementos envolvidos na competição e muitos outros fatores. Isto justifica os resultados diferentes encontrados na bibliografia, devendo-se destacar que inclusive na maioria das vezes, as cultivares de amendoim utilizadas foram diferentes.

Analisando-se o grupo de parcelas que tiveram um período inicial no limpo, pode-se observar que as parcelas mantidas no mato durante todo o ciclo apresentaram produções menores do que aquelas que receberam um controle inicial do mato, mesmo que fosse por apenas 10 dias. Comparando a produção média do tratamento no mato com a média daqueles que receberam um controle inicial, independente do período, observa-se um decréscimo de produção ao redor de $23,7 \%$ para o primeiro.

O comprimento do período no limpo não influenciou significativamente sobre o peso da produção de va- gens. O fato leva a crer num período total de competição abaixo de 10 dias. Este resultado, embora discorde com a quase totalidade da bibliografia estrangeira consultada, $(2,6,9,13,15,19,21$, 22 e 24), está de acordo com o único trabalho deste tipo encontrado na bibliografia nacional (Pacheco, 20). Isto leva a supor que para nossas condições (cultivar, solo, comunidade infestante e outros) a generalização feita por York e Coble (24), de que o amendoim é bem menos competitivo que outras culturas, e, portanto, mais susceptivel à presença das plantas daninhas, não é válida, uma vez que os níveis de infestação de plantas daninhas foram relativamente altos e as espécies predominantes são amplamente citadas na bibliografia nacional e estrangeira como de ocorrência generalizada nesta e em outras culturas comerciais. Isto também pode ser evidenciado no caso do período inicial no mato em que foram necessários

Quadro 2. Efeitos do período de competição de plantas daninhas sobre as produções de vagens e de sementes por parcela de $5,4 \mathrm{~m}^{2}$ e "stand" da cultura de amendoim, cultivar 'Tatu-53'. Média de 3 repetições.

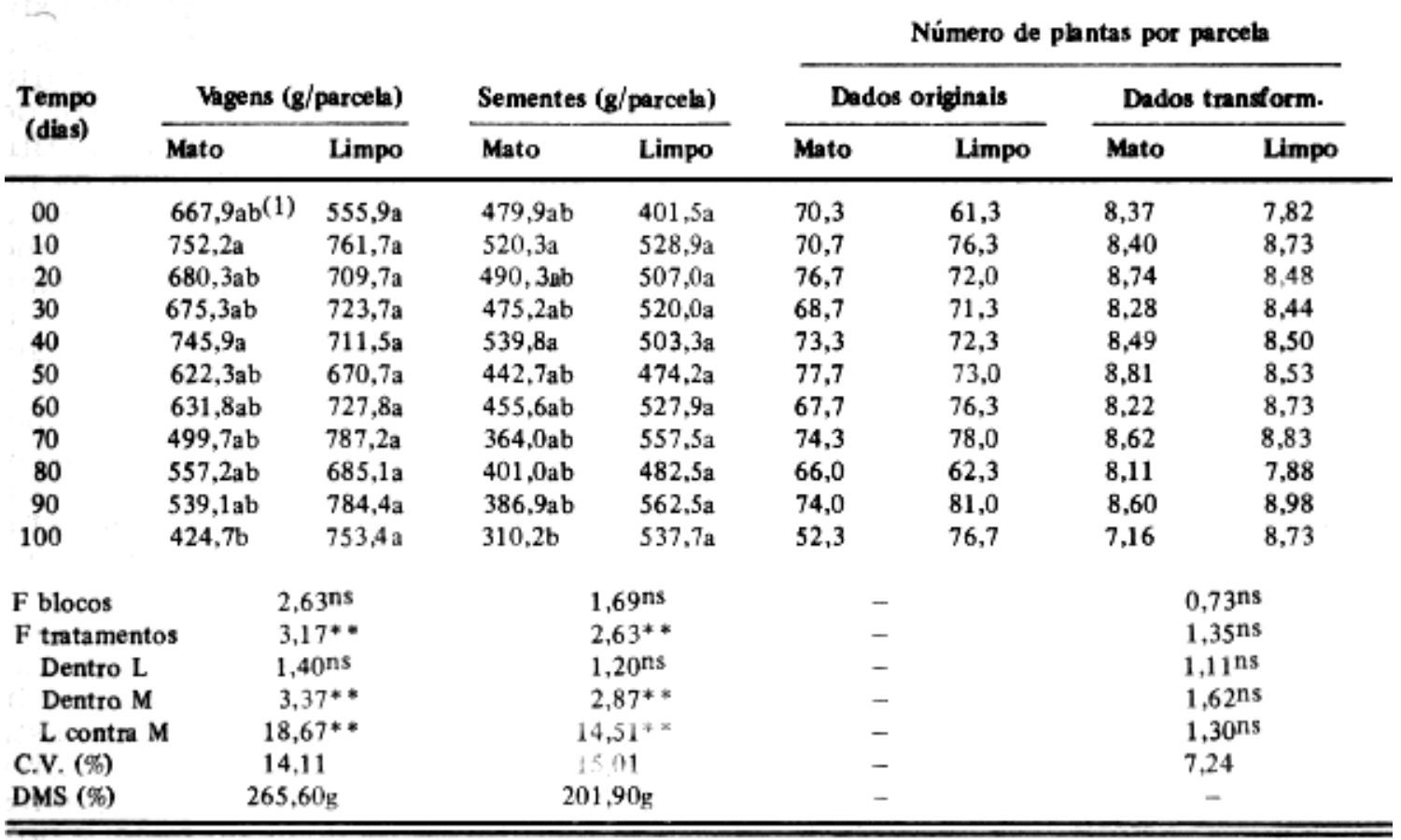

- significativo ao nível de $5 \%$ de probabilidade

(1) as médias acompanhadas de mesma letra não diferem estatisticamente entre si, ao nível de $5 \%$ de probabilidade. 
mais de 50 dias para que a competição, em relação à cultura, se efetuasse em termos de produção de vagens.

Após um período inicial no limpo, a própria cultura, através do sombreamento, controla o crescimento das plantas daninhas. Buchanam et al. (6) verificaram que, independente da extensão do periodo no limpo, a presença das plantas de amendoim sempre decresceu o crescimento de Cassia obtusifolia. Hauser et al. (13) observaram que plantas de Cassia obtusifolia que haviam germinado após a 4.a semana do ciclo da cultura, geralmente não conseguiram desenvolver-se, de modo a emergirem sobre a folhagem da cultura.

Não foi verificado correlação significativa entre a extensão do período no limpo e a produção de vagens $(\mathrm{r}==$ 0,530 . Esta correlação poderia ocorrer até o momento em que o período total de competição fosse atingido. A partir de então, a cultura passa a apresentar produções similares à testemunha capinada, independente do período de controle do mato, diminuindo o coeficiente de regressão linear. Este comentário concorda com as correlações calculadas em dados contidos em Hauser et al (13) e Hill e Santelmann (15). A única significância foi encontrada no experimento conduzido em Headland (13) no ano de 1971, sendo justamente este o único experimento em que o periodo total de competição atingiu uma idade mais avançada do ciclo de desenvolvimento da cultura. Esta mesma observação pode ser válida quando se comparam os dados destes autores com os de Hill e Santelmann (15) em que os períodos totais de competição atingiram o penúltimo e antepenúltimo períodos considerados, respectivamente em 1966 e 1967.

Não se observou também correlação significativa entre o comprimento do período no limpo e peso da matéria seca acumulada pelas plantas daninhas por ocasião da colheita da cultura $(\mathrm{r}==$ $0,55 \mathrm{~ns})$, indicando que com o desenvolvimento da cultura, o acúmulo da matéria seca pela comunidade infestante independe do tempo disponivel ao crescimento, sendo que estava limitado principalmente pelo sombreamento da folhagem do amendoim.

Dependendo das condições locais, muitas vezes é interessante prolongar as capinas por períodos maiores que $o$ período total de competição, a fim de evitar-se a interferência das plantas daninhas nas operações de colheita e secagem dos frutos no campo (15 e 8).

Drennam \& Jennings (8) consideram que quando a perda de produção de vagens da cultura do amendoim atinge $50 \%$ ocorre um equilíbrio entre a cultura e a comunidade infestante em termos de competição. $\mathrm{O}$ maior decréscimo de produção, na presente pesquisa, foi verificado quando comparou-se o grupo de parcelas com períodos no mato inferiores a 60 dias com aquele com períodos superiores a 70 dias, sendo de $25,9 \%$. Outros resultados obtidos na mesma localidade e solo não diferem muito, a saber, $35 \%$ (23) e $12 \%$ (18), exceção feita a Bianco (3) que encontrou um decréscimo de produção ao redor de $63 \%$. Este último autor trabalhou com a "cultura da seca" numa época em que a deficiência hídrica foi acentuada. Sabese que em condições desfavoráveis de umidade a cultura sofre mais intensamente os efeitos da competição (8 e 9).

$\mathrm{Na}$ presente pesquisa e na bibliografia nacional consultada, exceção feita a Bianco (3), pode-se verificar, que os efeitos da competição sobre a produção de vagens foram baixos em relação à literatura estrangeira. Este fato pode ser explicado pela possivel alta competitividade da cultivar utilizada nos trabalhos ('Tatu-53'), ou pelas con dições regionais que favorecem a cultura em relação à comunidade infestante, uma vez que as espécies predominantes são fartamente citadas na bibliografia como problemática a esta e outras culturas no Brasil e no mundo (Blanco, 5). A ocorrência dos dois fatos também é possivel.

O peso da produção de sementes por unidade de área foi afetado de maneira similar à produção de vagens por parcela, como se pode verificar pelos resultados da análise de variância e teste de Tukey. Não se verificou correlação direta entre o peso da produção de 
sementes por unidade de área e a extensão do período no limpo. Esta correlação existiu no caso da extensão do periodo no mato $\left(\mathrm{r}=0,84^{* *}, \mathrm{~s}=531,29\right.$-$1,78 \mathrm{t}$, onde $\mathrm{s}$ é o peso da produção de sementes por parcela) indicando que o peso da produção de sementes decresce proporcionalmente ao tempo em que a cultura permanece no mato, a partir da germinação. $E$ interessante ressaltar que comparando o coeficiente angular desta equação com aquele da produção de vagens por parcela, verifica-se que a produção de sementes é levemente menos sensivel à competição. Tal fato seria lógico se a porcentagem de casca também fosse negativamente afetada, o que já é citado na bibliografia (3, 6 e 17).

$\mathrm{Na}$ comparação entre a média das parcelas com periodos iniciais no mato inferior a 50 dias com aquela das parcelas com períodos superiores ou iguais a 60 dias, observa-se um decréscimo de produção de vagens ao redor de $26,0 \%$, enquanto que no caso da produção de sementes este valor foi de $22,0 \%$ indicando que também a porcentagem de casca havia sido alterada. $\mathrm{O}$ valor médio de porcentagem de casca do primeiro grupo de tratamentos foi $28,5 \%$, ao passo que no segundo grupo foi $27,6 \%$. Bianco (3) observa que o decréscimo na porcentagem de casca não é simplesmente o reflexo do inverso do crescimento das sementes no seu interior, mas que a própria casca é afetada na sua formação. E possivel que pela limitação dos recursos do meio, principalmente de luz, através do sombreamento, ocorra uma diminuição na quantidade de fotossintetizados e na translocação, diminuindo, portanto o acúmulo de celulose e hemicelulose na casca.

A análise de regressão múltipla com os três parâmetros da tabela, como era de se esperar, foi altamente significativa $\left(\mathrm{R}^{\prime}=0,99^{* *}\right)$. Pela equação $\mathrm{v}==211,38+$ $1,42 \mathrm{c}+7,07 \mathrm{~s}$, onde c é a porcentagem de casca, pode-se verificar que a produção de sementes foi o mais importante fator na determinação da produção de vagens. De fato estes dois parâmetros foram altamente correlacionados $\left(\mathrm{r}=0,99^{* *}, \quad \mathrm{v}=23,39+0,68 \mathrm{~s}\right)$. Não houve correlação entre a produção vagens ou de sementes e a porcentagem de casca.

Não se verificou efeitos da competição das plantas daninhas sobre a sobrevivência das plantas de amendoim, muito embora quando se compara parcelas que não receberam nenhuma capina com aquelas que tiveram um periodo inicial no limpo, independente da extensão deste, observa-se um "stand" $17 \%$ menor. Inclusive, não houve qualquer correlação entre o comprimento do período no limpo ou no mato com o "stand" da cultura. Já é conhecido na bibliografia o fato de que a competição altera em maior proporção a produtividade por indivíduo do que a própria sobrevivência das plantas (3). Hamdoum (10) observou um decrés cimo da produção de vagens de amendoim da ordem de $73 \%$ enquanto que o "stand" da cultura decresceu apenas 24\%. 0 decréscimo de produção por individuo foi da ordem de $55 \%$.

A produção de sementes por indivíduo, por sua vez, é função do peso médio das sementes, do número médio de sementes por vagem e do número médio de vagens por planta. Estes dados estão apresentados no Quadro 3.

$\mathrm{O}$ número médio de sementes por vagem não foi alterado significativamente pela competição imposta pelas plantas daninhas. Sabe-se que esta é uma característica varietal, sendo que para a cultivar utilizada este valor situase ao redor de 3,14 . Os valores ora observados são levemente inferiores àqueles citados, talvez devido ao fato de que não foi feita amostragem para este tipo de determinação e sim avaliadas todas as vagens de cada parcela experimental, inclusive aquelas que não possuiam sementes no seu interior.

Sendo esta uma caracteristica varietal, a única possibilidade da competição alterar a expressão deste parâmetro seria através da alteração do número de sementes abortadas. Ishag (17) verificou, em amendoim, que o maior efeito da competição das plantas daninh as foi sobre o enchimento das sementes e não sobre a viabilidade dos óvulos. Bianco (3), trabalhando com esta mesma cultivar, não encontrou qualquer efeito da competição sobre a 
proporção de sementes abortadas e, consequentemente sobre o número de sementes por vagem.

Hammertonn (12) acredita que um dos principais efeitos da competição das plantas daninhas é expresso sobre o florescimento e que este efeito pode alterar o número de sementes por vagem. Ishag (17) observou que a presença das plantas daninhas provoca uma certa desuniformidade no florescimento da cultura do amendoim. Acredita-se que devido a desuniformidade no desenvolvimento e na distribuição das espécies daninhas na área da cultura, as plantas de amendoim estarão sujeitas às mais diversas condições de sombreamento, de variações térmicas e hídricas do ar e do solo, competição por nutrientes, de liberação de exudatos radiculares e outros fatores que poderiam, direta ou indiretamente, alterar o florescimento. Assim, com desuniformidade de florescimento e, consequentemente, de frutificação, por ocasião da colheita, encontrar-se-ão vagens ainda em processo de formação. Com isso, pode ocorrer um aumento na proporção de vagens com uma ou duas sementes quando colhe-se uma parcela no mato ao lado de uma parcela no limpo, explicando, em parte, os resultados observados por Hammertonn (12). É claro que este efeito depende de muitos fatores como a susceptibilidade da cultivar de amendoim, a composição específica do mato, condições climáticas e outras.

Ainda no Quadro 2 pode-se observar que o número de vagens por planta foi alterado significativamente pela competição, acusado apenas no desdobramento dos graus de liberdade dos tratamentos. O grupo de tratamento com periodo inicial no mato apresentava valores significativamente menores em relação ao outro grupo de tratamentos. Não se observou qualquer correlação significativa entre as extensões dos periodos no mato ou no limpo

Quadro 3. Efeitos do período de competição das plantas daninhas sobre o número médio de sementes por vagem, número médio de vagens por planta e peso médio de 100 sementes de amen doim. Média de 3 repetições.

\begin{tabular}{|c|c|c|c|c|c|c|c|}
\hline \multirow{2}{*}{$\begin{array}{l}\text { Tempo } \\
\text { (dias) }\end{array}$} & \multicolumn{3}{|c|}{ Número de sementes/planta } & \multicolumn{2}{|c|}{ Número de vagens/phnta } & \multicolumn{2}{|c|}{ Peso médio de 100 sementes } \\
\hline & Mato & & Limpo & Mato & Limpo & Mato & Limpo \\
\hline 00 & 2,94 & & 2,93 & 6,84 & 6,89 & $33,71 \mathrm{ab}$ & 32,78 \\
\hline 10 & 2,98 & & 2,88 & 7,16 & 7,35 & $34,42 \mathrm{ab}$ & 32,81 \\
\hline 20. & 2,84 & & 2,92 & 6,39 & 7,38 & $35,43 \mathrm{a}$ & 32,89 \\
\hline 30 & 2,88 & & 2,92 & 6,70 & 7,18 & $36,03 a$ & 34,67 \\
\hline 40 & 2,96 & & 2,81 & 7,92 & 7,23 & $33,76 \mathrm{ab}$ & 34,42 \\
\hline 50 & 2,85 & & 2,99 & 5,54 & 6,78 & $36,45 \mathrm{a}$ & 32,36 \\
\hline 60 & 2,93 & & 2,89 & 7,39 & 7,33 & $31,46 \mathrm{ab}$ & 32,87 \\
\hline 70 & 3,02 & & 2,90 & 4,98 & 7,16 & $32,35 \mathrm{ab}$ & 34,41 \\
\hline 80 & 2,99 & & 2,97 & 6,37 & 7,25 & $31,33 \mathrm{ab}$ & 36,91 \\
\hline 90 & 2,91 & & 2,92 & 5,54 & 7,15 & $31,12 \mathrm{ab}$ & 32,22 \\
\hline 100 & 2,95 & & 2,90 & 6,20 & 7,35 & $29,84 \mathrm{~b}$ & 33,47 \\
\hline F blocos & \multicolumn{3}{|c|}{$1,21^{\text {ns }}$} & \multicolumn{2}{|c|}{$2,81^{n s}$} & \multicolumn{2}{|c|}{$2,96^{\mathrm{ns}}$} \\
\hline F tratamentos & \multicolumn{3}{|c|}{$1,00^{n s}$} & \multicolumn{2}{|c|}{$1,41^{\text {ns }}$} & \multicolumn{2}{|c|}{$2,47 * *$} \\
\hline Dentro L & \multicolumn{3}{|c|}{$0,70 \mathrm{~ns}$} & \multicolumn{2}{|c|}{$0,10^{\text {ns }}$} & \multicolumn{2}{|c|}{$1,34^{\text {ns }}$} \\
\hline Dentro $M$ & \multicolumn{3}{|c|}{$1,08 \mathrm{~ns}$} & \multicolumn{2}{|c|}{$2,06^{\text {ns }}$} & \multicolumn{2}{|c|}{$3,75 * *$} \\
\hline L contra $M$ & \multicolumn{3}{|c|}{$1,30^{\text {ns }}$} & \multicolumn{2}{|c|}{$7,89 * *$} & \multicolumn{2}{|c|}{$0,86^{\text {ns }}$} \\
\hline C.V. (\%) & \multicolumn{3}{|c|}{3,42} & \multicolumn{2}{|c|}{15,44} & \multicolumn{2}{|c|}{5,87} \\
\hline DMS & \multicolumn{3}{|c|}{-} & \multicolumn{2}{|c|}{-} & \multicolumn{2}{|c|}{$5,56 \mathrm{~g}$} \\
\hline
\end{tabular}

* significativo ao nivel de $5 \%$ de probabilidade

ns não signifficativo

(1) as médias acompanhadas da mesma letra não diferem estatisticamente entre si, a o nível de $5 \%$ de probabilidade. 
e o número de vagens por planta de amendoim (valores de $r$ de 0,47ns e 0,18 ns, res pectivamente. Ishag (17) havia verificado que em parcelas mantidas no limpo, o número de vagens por planta chegava a ser $50 \%$ mais elevado que em parcelas mantidas em competição com as plantas daninhas. Para o autor, o número de vagens por planta foi o principal fator da queda da produtividade da cultura devido à competição do mato. Encontrou ainda que o número de vagens por planta estava altamente correlacionada ao número de ramos e ao número de flores por planta, sendo que este último, também, foi função do penúltimo. Bianco (3) obse rvou uma redução média de $56,3 \%$ do número de vagens por planta devido à competição das plantas daninhas ratificando, em parte as conclusões de Ishag (17), uma vez que encontrou alta correlação entre este parâmetro e a produção de vagens por unidade de área $\left(\mathrm{r}=0,98^{* *}\right)$. No presente trabalho, esta correlação também foi encontrada no grupo de tratamento com período inicial no mato apenas com urna menor coeficiente de correlação linear $\left(r=0,69^{*}\right)$. Entretanto, esta correlação foi bastante alta quando se comparou com a produção de vagens por planta $\left(\mathrm{r}=0,92^{* *}\right.$, vi $=1,15+0,60$ nv, onde nv é o número de vagens por planta e a produção se sementes por planta $\left(r=0,94^{* *}\right.$, si $\left.0,91+0,88 \mathrm{nv}\right)$. Sendo que a produção de sementes por planta foi o fator preponderante da produção de sementes por unidade de área, pode-se sugerir o mesmo tipo de conclusão no presente trabalho, urna vez que não se encontrou correlação direta entre este parâmetro e o número de sementes por vagem $(r=0,06 n s)$ e, também com relação ao peso médio de 100 sementes ( $r=0,40 n s)$.

O peso médio de 100 sementes, por sua vez, sofreu influência significativa da competição das plantas daninhas. O desdobramento dos graus de liberdade mostrou um peso significativamente maior em parcelas com período inicial no limpo. Além disso, dentro do grupo de tratamento com um periodo inicial no mato ocorreram contrastes significativos. A correlação entre a extensão do período inicial no mato e o peso médio de 100 sementes foi significativa $\left(\mathrm{r}=0,75^{* *}, \mathrm{p}=35,74-\right.$ - 0,05 t, onde $p$ é o peso de 100 sementes), indicando que o tempo de competição a partir da germinação da cultura influencia negativamente o acúmulo de matéria em sementes de amendoim. Tal fato pode estar relacionado a efeitos da competição sobre a translocação de materiais para formação das sementes, à limitação da fotossíntese da planta, não tendo material para enchimento das sementes ou à desuniformidade no florescimento e/ou frutificação, sendo que na colheita obteve-se sementes em pleno processo de formação (Hammertonn, 1976).

Bianco (3) observou que a competição das plantas daninhas alterou a granação das sementes do amendoim, diminuindo em $13,9 \%$ a porcentagem de sementes granadas e aumentando em $40,3 \%$ a porcentagem de sementes mal granadas. Is hag (17) verificou que os efeitos da competição foi sobre o enchimento das sementes de amendoim, uma vez que em determinados tratamentos em que a cultura era mantida livre da competição por certo intervalo de tempo, o florescimento era normal, mas o peso médio por 100 sementes era diminuído sensivelmente. Tal fato, também foi ressaltado por York e Coble (24), os quais verificaram um período tardio crítico de competição de plantas em amendoim, sugerindo efeito da competição, sobre a fixação dos frutos e/ou enchimento das sementes.

Rodrigues Marquina et al. (22) verificaram que periodos maiores de 50 dias de convivência múltipla entre a cultura do amendoim e a comunidade infestante, promoviam efeitos sensiveis na produção e que este fato estava correla cion ado ao periodo ligeiramente posterior do máximo florescimento da cultura que ocorreria entre 40 e 50 dias, época de formação dos frutos e sementes. Estes resultados concordam com os verificados no presente trabalho. A média dos tratamentos que tiveram periodos no mato de até 50 dias foi de $34,97 \mathrm{~g}$ por 100 sementes, ao passo que, em períodos maiores no mato, a média foi de 31,22 g. Além disso, considerando-se 
que para nossas condições e para a cultivar utilizada, o período de florescimento é similar ao encontrado por Rodriguez Marquina et al. (22), estudou-se a correlação entre o tem po de competição anterior aos 60 dias e o peso médio de 100 sementes. O coeficiente de re= gressão linear não foi significativo $(r=$ $=0,56 \mathrm{~ns})$. Contudo, quando o período de competição considerado foi superior ou igual a 60 dias, a correlação foi altamente significativa $(\mathrm{r}=0,78 * *, \mathrm{p}=$ $=34,80-0,045 \mathrm{t}$ ). Isto sugere que realmente o período de formação do fruto e da semente é bastante sensivel à competição das plantas daninhas. Deve-se esclarecer que, embora a bibliografia consultada não mostre claramente, também a desuniformidade de florescimento e, conseqüen temente, de maturação dos frutos, contribui para o decréscimo do peso médio das sementes de amendoim submetidas à competição das plantas daninhas.

\section{LITERATURA CITADA}

1. Aloisi, R.R. \& Demattê, J.L.I.. Levantamento dos solos da Faculdade de Medicina Veterinária e Agronomia de Jaboticabal. Cientifica 02:123-136; 1974.

2. Bhan, V.M.; Singh, M. \& Maurya, R.A.. Crop Weed Competition Studies in Grouddnuts. Indian Journal of Weed Science 03:32-36, 1971.

3. Bianco, S.. Matocompetiçăo em amendoim das "secas" sob diferentes condiçoes de adubaçáo. Jaboticabal, FCAV/UNESP, 1978. 66p. (Trabalho de Graduaçāo).

4. Blanco, H.G.. A importáncia dos estudos ecológicos nos programas de controle das plantas daninhas. Biologico 38:343-350, 1972.

5. Blanco, H.G.. Catálogo das espécles de mato infestantes de áreas cultivadas no Brasil. Campinas, CECORT/CATI, s/p 1978.

6. Buchanan, G.A.; Hauser, E.W.; Etheredge, w. J. \& Cecil, S.R.. Competition of Florida beg. garweed and sicklepod with peanut II. Effects of cultivation, weeds and SADH. Weed Science 24:29-39, 1976.

7. Bunting, A.H. \& Lea, J.D.. The ecology and control of weeds at Tozi in East Central Sudan. Empt. Journal Experimental Agricultural, 25:40-50, 1957.

8. Drennan, D.S.H. \& Jennings, E.A. Weed competition in irrigated cotton (Gossypium bar. badense L.) and groundnut (Arachis hypogaea L.) in the Sudan Gezira. Weed Research, 17:03-09, 1977.
9. Feakin, S.D.. Ed. Pest Control in Groundnuts. $3 .^{\text {a }}$ ed. London, Center for Overseas Pest Research, 1973. $197 \mathrm{p}$.

10. Hamdoun, A.M. Competitive effects of weeds upon growth and yield of cotton, groundnuts and sorghum in the Kenana area of the Sudan. Zeitschrift Mir Pllanzenkrankheiten und Pflanzenschutz 84:509-515, 1977. Apud: Weed Abstracts 27(7):2324, 1978.

11. Hammertonn, J.L.. Weed control work in progress at the University of the West Indies. Part 4. PANS 20:429-436, 1974.

12. Hammertonn, J.L.. Problems of herbicide assessment in peanuts in Jamalca. Weed Research, 16:27-35, 1976 .

13. Hauser, E.W.; Buchanan, G.A. \& Ethredge, W.J.. Competition of Florida beg. garweed and Sicklepod with peanuts. I. Effects of periods of weed-free maintenance or Weed competition. Weed Science 23:368$-372,1975$.

14. Hauser, E.W. \& Parham, S.A.. Effects of annual weeds and cultivation on the yield of peanut. Weed Research 09:192-197, 1969.

15. Hill, L.V. \& Santerlamann, P.W.. Competitive effects of annual weeds on spanish peanuts. Weed Science 17:01-02, 1969 .

16. Holm, L.G.; Plucknett, D.L.; Pancho, J.V. \& Herberger, J.P.. The World's Worst Weeds. Honolulu, University Press of Havaii, 1967. p.609.

17. Ishag, H.M.. Weed control in irrigated groundnuts (Arachis hypogaea L.) in the Sudan Gezira. Journal of Agricultural Science 77: 237-242,1971.

18. Levi, R.. Herbicidas em pré-plantio incorporados na cultura do amendoim. Jaboticabal, FCAV/UNESP. 1975, p. 43. (Trabalho de Graduação).

19. Oran, P.A. Experiments on the control of weeds on groundnuts in Tripolitania. Weed Research 01:211-228, 1961.

20. Pacheco, Rosilux P.B.. Duraçáo do período da competição de malerbas com a cultura do amendoim das águas (Arachis hypogaea L.). Ciência e Cultura 29:559, 1977, (Suplemento).

21. Rethinam, P.; Selcarangaraju, G.; Sankaran, N.; Sankaran, S. \& Morachan, Y.B.. Studies on crop-weed competition and Chemical weed control in groundnut. Madras Agricultural Journal 63:454-457, 1976.

22. Rodrigues Marquina, E.L.; Hemsy, V.; Scandaliaris, J.; Munoz, H.L. \& Cajaz, J.A.. Periodo crítico de competência entre las malezas y el cultivo del mani (Arachis hypogaea L.). Revista Agronomica del Noroeste Argentino $11: 137-143,1974$

23. Sader, R. Controle químico de plantas daninhas na cultura do amendoim (Atachis hypogaea L.). Piracicaba, ESALQ/USP. 1975. p.122 (Dissertaçáo de Mestrado).

24. York, A.C. \& Coble, H.D.. Panicum interference in peanut. Weed Science 25:43-47, 1977. 